\title{
PROBLEMS ASSOCIATED WITH SUBSTANDARD AND COUNTERFEIT DRUGS IN DEVELOPING COUNTRIES: A REVIEW ARTICLE ON GLOBAL IMPLICATIONS OF COUNTERFEIT DRUGS IN THE ERA OF ANTI-RETROVIRAL
} (ARVS) DRUGS IN A FREE MARKET ECONOMY

\author{
Stephen E. D. Nsimba
}

\begin{abstract}
Objectives: To review the global implications associated with the use of substandard and or counterfeit drugs in developing and may be developed countries. The focus of this review is particularly on antiretroviral (ARVs), antimalarials and other drugs.

Methods: Review of various literatures through Pub-Med, Medline, Google and Internet search to retrieve and download published materials was done by the author of this review paper.

Results: When patients receive a counterfeit medicines, they are subjected to multiple risks. They often suffer more than just an inconvenience; as they become victims of fraud medicines and are all put at risk of adverse effects from unprescribed medicines or substandard ingredients. Additionally, patients may lose confidence in health care professionals including their physician and pharmacist, and potentially modern medicine or the pharmaceutical industry in general. Counterfeit or substandard (poor quality) drugs pose threats to society; not only to the individual in terms of the health side effects experienced, but also to the public in terms of trade relations, economic implications, and the effects on global pandemics. It is vital for suppliers, providers, and patients to be aware of current trends in counterfeiting in order to best prepare for encounters with suspicious products. Furthermore, this is an issue that needs to be continually dealt with on national and international policy levels. Developing countries should try their level best to establish good laboratories for monitoring and checking quality of all pharmaceuticals manufactured locally and those imported or donated to these countries. The Ministries of Health and all stakeholders involved in this issue must ensure that all drugs meet the set or established international standards and national standards. Failure to do so will be to misuse the hard earned forex that is normally borrowed from banks for the procurement and distribution of drugs to its people. Indeed sub-standard medications do more harm than good to people's health and it is unethical to give such drugs to people. Of course, in any market, some corruption and fraud always exist, but there are few commercial markets where fraud can have such drastic impact on global health and welfare. It is essential, therefore, that a multi-faceted approach be used to control this problem which affects the international community and continuously threatens the health of millions of people especially in developing countries.

Conclusion: Developing countries should try their best at all costs establish good laboratories for monitoring or checking for quality control for all pharmaceuticals locally manufactured and those imported (entering) or donated to countries to make sure that they meet the set or established international or national standards. Short of that countries will be wasting a lot of money using forex which has been borrowed in a form a loans procuring and distributing to its people sub-standard medications which will do more harm than good to its indigenous people and this is unethical per se to give people drugs not meeting required set international standards.
\end{abstract}

Key words: Counterfeit, sub-standard drugs, ARVs, antimalarials, other drugs, drug companies, developing and developed countries

\section{Introduction}

The practice of using medicinal agents to improve health has existed for thousands of years, but it was not until the last century that the manufacturing and distribution of pharmaceuticals became widespread. The last few decades alone have seen an exponential increase in the number of commercially available pharmaceutical products. Along with the multitude of health benefits that have resulted from this phenomenon are unique challenges. The most pressing issue for many people is that of access; despite amazing advancements in medicine, the potential health benefits of drugs are lost if people do not have access to them because of cost or other constraints. According to the American Association of Retired Persons (AARP), one of the most significant concerns among the elderly in the United States is their ability to affordably access prescription drugs (1). While this is a major issue in the U.S., it is much more problematic for the rest of the world. Americans may struggle to afford maintenance medications for chronic diseases, but in many other parts of the world, particularly developing countries, many people do not even have access to treatment for acute infectious diseases such as malaria, tuberculosis, and cholera.

Correspondance to: Stephen E. D. Nsimba, P. O. Box 65010, Muhimbili University of Health \& Allied Sciences (MUHAS), School of Medicine

Department of Clinical Pharmacology, Dar-es-Salaam-Tanzania-East Africa., Tel 255-22-2150302-6, Mobile 0741318113, Fax 255-22-2153389/2150465, Email: nsimbastephen@yahoo.co.uk or snsimba@muchs.ac.tz
Because so many people are afflicted by untreated health conditions worldwide, the drugs that can provide benefit have become an extremely sought-after commodity. The market for pharmaceuticals is extremely competitive since the sale of such products has become so lucrative, both in the U.S. and globally. As with the sale of any type of goods, individuals and companies are always looking for ways to maximize profits, and one of the simplest ways to do this is to decrease costs. One way to achieve this goal, albeit illegal, is to manufacture or distribute drugs that contain substandard amounts of the active ingredient. This dimension of counterfeiting is possible because methods of detecting such drugs are difficult for the end user. If a pharmaceutical product is defective, it is often difficult for patients or even sellers to identify because treatment response is somewhat subjective. Furthermore, drug counterfeiters are often able to make products that are incredibly similar in terms of shape, color, and likeness, and it can sometimes require very sensitive scientific means to determine a counterfeit product. Creating products with none or a decreased amount of the labelled active ingredient is not the only form of counterfeiting. Mislabelling a drug product with a different brand name or expiration date are other examples of this phenomenon. 


\section{Available Data}

The prevalence of counterfeit drugs in the global marketplace is reaching epidemic proportions; with developing countries disproportionately affected to a greater degree (2). Developing countries often do not impose the same level of regulations of pharmaceutical product quality in the same extent as developed countries do. Furthermore, the security measures and tests that can be employed to identify counterfeit drugs can be extremely costly and difficult to implement, and many of these countries simply do not have enough resources to use these techniques consistently. In addition to these issues, the general demand for pharmaceuticals can be much higher in developing countries than in developed countries, particularly for acute life-threatening conditions. These needs can create a sense of urgency and desperation, causing people to sacrifice more to attain the treatments that they believe will save their lives and those of their families. The combination of these factors ripens the atmosphere in developing countries for drug counterfeiting.

Due to the difficult nature of identifying counterfeit drugs, estimates on prevalence are not precise, but they give valuable insight to the scope of the problem. The World Health Organization has estimated that approximately 10 percent of the global pharmaceuticals market consists of counterfeit drugs, but this estimate increases to $25 \%$ for developing countries, and may exceed $50 \%$ in certain countries (3). Considering potential outcomes of receiving counterfeit drugs, including lack of successful treatment, adverse effects, and even death, these numbers are staggering. What is even more alarming is that these numbers represent growth in recent years. In the past several years, the number of counterfeit drug cases that the FDA has opened has been increasing (4) (Figure 1). This may be in part due to higher surveillance, but a true increase in prevalence is likely, and considering that the U.S. underrepresents the global outlook, this rising trend is probable elsewhere and perhaps seen at even higher rates of increase.

Figure 1 - Counterfeit Drug Cases Opened by FDA per Year

\section{Counterfeit Drug Cases Opened by FDA per Year}

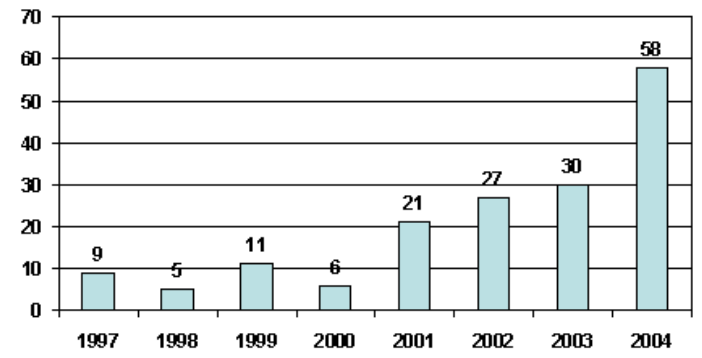

Previously reported data for FY 1997-2003 were revised due to new information indicating involvement of counterfeit drugs in other previously uncounted criminal investigations (4).

Not only is the prevalence of counterfeit drugs higher in developing countries, but also the drugs are typically more essential to life-threatening conditions. In a developed country such as the United States, some drugs that are commonly counterfeited include those that are passed off as Viagra ${ }^{\circledR}$ (sildenafil citrate manufactured by Pfizer) for the treatment of erectile dysfunction, and Lipitor ${ }^{\circledR}$ (atorvastatin calcium manufactured by Pfizer) for the treatment of elevated cholesterol (4). While counterfeiting incidents for these drugs can potentially produce serious adverse events, if the ingested product results in a lack of effective treatment, the patient's life may not be in jeopardy. In contrast, the most sought-after drugs in developing countries, and therefore the most likely to be counterfeited, include those for the treatment of more serious conditions such as malaria or AIDS. The risk of taking a counterfeit medication for one of these conditions not only poses health risks based on whatever ingredients are in the product, but also a more serious outcome due to the lack of effective treatment. As stated earlier, the average estimate of counterfeit prevalence globally is approximately $25 \%$, but some countries carry a much heavier burden than others. In Kenya, for example, where malaria is a major public health concern, causing approximately 26,000 deaths in children under the age of five, counterfeited anti-malarial drugs is a major problem (5). A recent study that analyzed samples of the two most common anti-malarial drugs in Kenya, sulphadoxine-pyrimethamine (SP) and amodiaquine (AQ), found that about $40 \%$ of these drugs available for sale were of substandard quality (5).

Furthermore, a high incidence of sub-standard drugs on the market has been reported in developing countries (6). This is often attributed to counterfeiting. In a controlled study done in Nigeria and Thailand, samples of chloroquine and selected antibiotics from pharmacies were analyzed using appropriately validated methods based on High- Performance Liquid Chromatography (HPLC). The results indicated that $36.5 \%$ of the samples were sub-standard with respect to pharmacopoeial limits. Decomposition was the cause of poor quality in a number of samples but overall poor manufacturing appeared to be prevalent. The analyses generated little evidence to implicate fraudulent manufacturing. It was suggested that treatment failure and drug resistance are possible consequences of the use of sub-standard drugs (6).

Studies assessing the quality of anti-malarials (chloroquine and sulfadoxine / pyrimethamine) in Yemen, the results indicated high and low failures in ingredient content for chloroquine tablets and chloroquine syrup. There was some dissolution failure for chloroquine tablets and high sulfadoxine / pyrimethamine tablets dissolution failures. It was feared these medicaments could have reduced therapeutic effectiveness and lead to the development of drug resistance (7). The quality of essential antimicrobial and anti-malarial drugs; amoxicillin capsules, metronidazole 
tablets, sulfamethoxazole/trimethoprim tablets, quinine tablets and sulfadoxine/pyrimethamine tablets in Rwanda and Tanzania was assessed. It was established that some of these drugs were substandard at time of purchase, deteriorated during storage under simulated tropical conditions and had a poor in-vitro drug release (8).

In Uganda, poor quality of drugs at various distribution points has also been reported. It was noted that a significant proportion of chloroquine on the Ugandan market did not meet the required pharmacopoeia quality standards (9). The study noted that even though there was routine inspection and analysis of the incoming drugs for content of the active ingredients and other pharmaceutical properties by the National Drug Authority (NDA), more vigilance and routine checks of the drugs on the market was a necessity. This is because some batches of drugs find their way in to the country unofficially and storage facilities are not up to the appropriate standard. The above studies suggest quality issues of all drugs including ARVs.

In Tanzania, it was established that some drug formulations imported into the country were not optimized for stability in a tropical country. It was demonstrated that the dissolution rate of two diclofenac formulations reduced significantly during storage under class four conditions (40C, 75\% relative humidity) (10). These are some of the few known examples of high rates of counterfeited drugs in developing countries, but represents a larger global concern.

\section{Methods and motivations of drug counterfeiters}

If drug counterfeiting is not curbed in some way, the problem is likely to continue or worsen because of its highly profitable nature. Profits are the single most important motivating factor for drug counterfeiters, and so far they have proven many of their endeavors not only worthwhile but also capable of expanding. According to the Centre for Medicines in the Public Interest, counterfeiting represented approximately $10 \%$ of the global pharmaceuticals market, with sales exceeding \$35 billion (U.S. currency) (11). Perhaps the more startling realization is that this figure represents a steady increase from previous years. As legitimate sales rise, counterfeit sales are expected to increase as well, and it has been projected that global sales of counterfeit sales may reach $\$ 75$ billion by 2010 (Table 1). These estimates are based on past data, but the possibility exists of counterfeiters expanding their production and utilizing increasingly advanced technology, which may allow them to increase their sales even beyond what is projected.

There is a wide range of methods of counterfeiting pharmaceutical products, ranging from little or no active ingredient to the wrong ingredient, or mislabelling. Perhaps the most traditional method of counterfeiting drugs is to create a product that looks similar to a particular popular selling brand name medication, but containing none of the active ingredient. While many counterfeiters employ this method, it may be detected somewhat easily, and therefore more advanced methods have been developed.

Another method is to include substandard amounts of the active ingredient, or for a generic manufacturer to make a product and sell it as the brand name in order to increase revenues. Sometimes counterfeiters use one active ingredient and label it as another, or change some other part of the labelling such as the expiration date for products that are beyond their initial expiration date. As these methods and technologies become more advanced, it becomes increasingly difficult to detect a fraudulent medication. Patients may not ever realize that they are taking a fake, or they may only realize after taking it for some time and experiencing either lack of treatment or an adverse event.

Counterfeit products can range from very poorly resembling a branded product to being so similar in likeness that it is virtually impossible to detect the difference. If fraudulent products are suspected, certain tests can be used to help determine the contents. These tests include, but are not limited to, colour reactions, spectrophotometry, and various types of chromatography, including thin-layer, gas, and highperformance liquid chromatography (12). Some of these tests are relatively inexpensive, such as colour reactions and thin-layer chromatography, but as the technology of the counterfeiters increase, more expensive tests may be needed to detect a fraud. Furthermore, sometimes pharmaceuticals are made to be so similar to brand name products that it is virtually impossible to prove that they are not authentic, sometimes even by the brand name manufacturer. This presents yet another challenge for regulators who seek to curb the production of these illegal products.

Table 1 - Global Pharmaceutical Commerce Estimates

\begin{tabular}{lllllllll}
\hline & $\mathbf{2 0 0 4}$ & 2005E & 2006E & 2007E & 2008E & 2009E & 2010E & CAGR \\
\hline Counterfeiting & $\$ 35.20$ & $\$ 39.07$ & $\$ 43.76$ & $\$ 49.45$ & $\$ 56.37$ & $\$ 64.83$ & $\$ 75.20$ & $13.0 \%$ \\
Growth & $10.0 \%$ & $11.0 \%$ & $12.0 \%$ & $13.0 \%$ & $14.0 \%$ & $15.0 \%$ & $16.0 \%$ & \\
$\begin{array}{l}\text { Percent of Total } \\
\text { Total Intl. }\end{array}$ & $10.7 \%$ & $11.4 \%$ & $12.0 \%$ & $12.5 \%$ & $13.0 \%$ & $13.6 \%$ & $14.2 \%$ & \\
$\begin{array}{l}\text { Commerce } \\
\text { Growth }\end{array}$ & $\$ 328.97$ & $\$ 342.74$ & $\$ 364.67$ & $\$ 395.60$ & $\$ 433.63$ & $\$ 476.68$ & $\$ 529.58$ & $7.5 \%$ \\
\hline
\end{tabular}

Source: Author's calculations. ${ }^{1}$ 
Some countries have a greater capacity for handling the prospect of counterfeit drugs than others. As medicines continue to become more widely available and advanced in treating diseases, it should be easier to identify counterfeits if they lack active ingredients. That is, as access to medicines improves and more patients are reached, a greater knowledge base is expected, and patients and health professionals should become more aware of treatment outcomes and therefore recognize failures. Some countries, particularly the United States, already have strict trade and patent regulations in place, which may not only play a role in increasing costs but they also help to decrease counterfeit activity. Furthermore, the technology that makes counterfeiting drugs more difficult exists. The World Health Organization has been playing a strong role in aiding countries in their anti-counterfeit efforts, and the World Trade Organization helps to regulate international drug trade. All these are strengths that can be utilized in combating the global problem.

\section{Weaknesses}

Many weaknesses in the fight against fraudulent selling of pharmaceuticals exist, in part because this phenomenon is somewhat new, and policymakers and regulators are somewhat "catching up" to counterfeiters. As these criminals continue to use more advanced and newer technologies, countries have to continuously respond to these threats, and because counterfeiting is inherently deceptive, the problem is often large-scale before one is clearly identified. A major global weakness is the issue of international trade. Often free trade zones pose a problem. The lack of consistent enforced trade regulations also causes counterfeiting to be more prevalent in some countries than in others.

Along that same line is the issue of international copyright laws which allow so many different forms and brands of the same drug that it can be difficult to know which manufacturers and distributors to trust. Furthermore, the enormous demand for pharmaceuticals in certain areas, particularly developing countries, opens the door for more corruption and fraud. Areas of high demand cause people to be desperate for medications, and also allow suppliers to benefit from higher profit margins. Stock-outs and the black market compound this problem in developing countries, which are often the countries that would benefit the most from authentic medicines, and are harmed the most by fraudulent activity.

\section{Opportunities}

One of the greatest opportunities, particularly in developing countries is advancing technology. This was already listed as strength, but because it has not been implemented fully, it also remains as an opportunity. For developing countries, the opportunities that will bring the most benefit are those involving stricter product standards with regards to quality control and trade regulations. Another opportunity is that of improving infectious disease treatment by inhibiting counterfeit activity. This may seem rather indirect, but if fraudulent activity can be constrained, then a greater percentage of patients taking medication for the treatment of such diseases as HIV/AIDS, influenza, and vaccinepreventable infectious diseases will actually be benefiting. This will help eliminate the problem of those who believe they are seeking treatment but are actually receiving inadequate treatment and contributing to further spread of the disease and resistance.

\section{Threats}

Counterfeit drugs pose many far-reaching threats to overall global health. They put individuals at risk of experience adverse events or not achieving treatment goals, and also contribute to public health by aiding in the spread of infectious diseases. The prevalence of substandard or fraudulent medications threatens the relationship between patients and their prescribers, pharmacists, and other suppliers. Patients may begin to lose faith in modern medicines altogether if they are harmed or if they do not benefit from them and may cause some people in developing countries seeking alternative medicines such as traditional remedies. Fraudulent activity also threatens the strength of the global marketplace, causing various parties in the supply chain to become distrustful of others, and possibly contribute to nationalism.

\section{Global Implications}

While the data on prevalence of counterfeiting drugs is startling, the real issues are the global health implications that are a result. One may argue that if it is so difficult to identify the counterfeits, then patients must not be suffering. The reality, however, is that millions of people worldwide have been affected by the perils of fraudulent pharmaceuticals, particularly in developing countries. One of the biggest disasters related to counterfeit pharmaceuticals was a case of vaccines given as a gift to the country of Niger from neighbouring Nigeria in 1995 to help contain the meningitis epidemic there (13). The vaccines did not contain any active ingredient, but more than 50,000 people received the vaccine and this subsequently led to 2,500 deaths, according to the World Health Organization (3). This is one of the few documented cases of counterfeited products causing deaths on such a large scale, but there are other cases of large-scale counterfeiting schemes in which it is more difficult to estimate directly related deaths.

If drugs for HIV and AIDS are counterfeited, for example, it would be difficult to directly attribute deaths to the defective products due to the relatively long course of the disease. Considering that approximately 40 million people are living with HIV today (14), this presents enormous opportunities for drug counterfeiters to profit without easily being exposed. Anti-retrovirals (ARVs) used in the treatment of HIV and AIDS are targets that have the potential for the greatest global impact, but other diseases and conditions are always possible targets as well. With increasing concerns about the possibility of a global avian flu pandemic, experts are already 
considering the counterfeiting of drugs such as Tamiflu ${ }^{\circledR}$ (oseltamivir phosphate) to be a substantial threat (15).

It is also important to mention that due to its discretionary nature, drug counterfeiting is likely highly underreported. This is due not only to the fact that not all fraudulent products are identified, and governments in developing countries do not have the resources and capacity to fully regulate the market, but also because there are certain media-related barriers to reporting incidents. Pharmaceutical manufacturers are extremely reluctant to publicize reports of counterfeit medications, because consumers may begin to lose confidence in the brand name if they fear that the product may not be authentic. Prescribers and consumers may also believe that the brand name manufacturer is failing in their security measures if they view their products as being easily counterfeited. Not only are manufacturers hesitant to report suspected counterfeiting to the public, but governmental agencies may also be reluctant. They may fear that their regulatory authority may seem insufficient or that they are not upholding their responsibility of protecting citizens from harm and fraud.

Whether people learn about counterfeit drugs from the media, the government, or have a personal experience with such products, there is another very detrimental consequence that may often be overlooked. People may begin to lose faith not only in certain brand names, but also in the value of taking drugs altogether to treat their illnesses. This could be especially dangerous in developing countries, where infectious diseases are much more prevalent. If patients decide not to take medications due to distrust of manufacturers, governmental agencies, or health care professionals, they not only endanger their own health, but it also becomes a greater public health concern if they remain infectious. This can also be a bigger problem in developing countries since people often spend more of their income on pharmaceuticals, and they may be less likely to spend their already limited income on drugs that may be ineffective or potentially harmful.

\section{Current Strategies}

Although the current situation seems overwhelming, federal governments and international organizations such as WHO have employed strategies to reduce illegal activities. A country with one of the lowest rates of counterfeiting is the United States, in part due to the regulatory capacity of the Food and Drug Administration (FDA). Aside from already present strict standards on drug quality and patent protection, the FDA has appointed a special task force for this specific purpose and focused attention on the issue. They released a report entitled "Combating Counterfeit Drugs" in February 2004, outlining an eight-part approach to containing this problem in the country. The eight steps are as follows: (a) Implementing new technologies to increase drug supply security, (b) Adopting electronic track and trace technology, (c) Adopting and enforcing strong state-driven anti-counterfeiting laws and regulations, (d) Increasing criminal penalties to deter and punish counterfeiters, (e) Adopting secure business practices in the supply chain, (f) Developing a more comprehensive reporting system, (g) Educating consumers and health professionals, and (h) Collaborating with foreign stakeholders to advance global initiatives (16). While some of these components are already in place to a certain degree, such as regulations and penalties, others will need some active development. One of the most important and potentially effective parts of this approach is the technological aspect. This is not just a federal responsibility, but one of individual manufacturers as well. Some companies already have begun to heighten security in this regard by adding holograms or other brandings on products that are difficult to replicate. Perhaps one of the most overlooked but potentially helpful components is that of educating consumers and health care professionals. Even if the most highly advanced security measures are implemented, fraud can still occur if people do not know what they need to be aware of. Furthermore, it is important for open communication to exist not only between patients and providers to report adverse events or lack of efficacy, but also for health professionals to participate in the reporting process. Medwatch, which is the FDA's reporting system for adverse events, also includes a forum for reporting suspicious products, but they are likely highly underreported. This assumption is made based on the underutilization of the Medwatch system for adverse events; health care professionals often cite lack of time as a reason for not reporting incidents, but they need to be continuously educated on the importance of reporting suspicious activity.

WHO has also implemented its own strategy for overcoming the problem globally, issuing a report in 1999 entitled "Guidelines for the Development of Measures to Combat Counterfeit Medicines" (17). Due to the global nature of their approach, it is much more comprehensive than the strategies of individual countries, but it takes into account the same general principles as the FDA's strategy, albeit on a larger scale. The guidelines that WHO presents are focused on aiding countries in their own anti-counterfeit and regulatory initiatives, including implementing individual national policies, improving and enforcing regulations, testing suspicious products, and improving technology. One of the ways that they achieve this goal is by implementing training programs for testing products as well as enforcing international regulations. A broad but extremely important goal for WHO is to help countries that share a common marketplace to forge partnerships and work together to curb the problem. For the United States, where the drug supply is largely self-contained, this is not a major issue, but in many other countries throughout the world, reliance on other nations and international trade needs to be addressed.

\section{The Way Forward for Future Opportunities}

As stated earlier, one of the most significant opportunities for developed countries will be technology advancements. This includes, but is not limited to, increasing the utilization of unit-dose packaging, tamperevident packaging, unique labelling such as specific inks or holograms, and some sort of track-and-trace tag or unique chemical marker (16). Pilot studies are underway 
to evaluate the use of electronic devices that could be implanted to packages and be scanned at various points of the supply chain to ensure authenticity. This radio frequency identification technology (RFID) has garnered a great deal of support due to its potential for accurately tracing products. It would also be beneficial for other reasons, namely inventory control and aiding in product recalls. At this time it is cost-prohibitive and regulations regarding its use are still being developed, but it shows great promise (17). While some of these technologies are already in place, further utilization, particularly from products that are most likely the targets for counterfeiting, would be beneficial in combating fraud. Another major opportunity for improvement, not only for developed countries but also for developing countries, is communication and education among suppliers, providers, and patients regarding what to be aware of when selling, dispensing, and taking medications.

International opportunities, particularly for developing countries, include those mentioned in the current strategies section outlined by WHO. Stronger regulations and stricter control of pharmaceutical products is the cornerstone for minimizing fraudulent activity. Enabling countries to set and enforce stricter national policies will be particularly beneficial to strengthening individual economies and may allow international trade to be controlled more consistently. Continual efforts to train suppliers and dispensers in identifying potentially counterfeit products, as well as an avenue to report suspicious activity and employ tests to determine authenticity can also be employed. Eventually the ability to employ the types of technology that are imminent in developed countries may become possible globally as well. There is no single strategy that will effectively eradicate pharmaceutical counterfeiting, but rather a multi-faceted approach such as those designed by the U.S. FDA and the WHO are the best opportunities for solving this complicated problem.

However, there are difficulties encountered in implementing the ART programs in most developing countries which includes among others, drug quality (18). ARVs have to be transported to the accredited centers and subsequently stored in the hospital storage facilities. The prevailing tropical conditions (high temperature combined with high humidity) can have an undesirable effect on the biopharmaceutical properties of these drugs. Quality assurance along the supply chain is very important. This ensures that the patients receive safe and efficacious drugs for treatment of HIV/AIDS.

In conclusion, developing countries should try their best at all costs establish good laboratories for monitoring or checking for quality control for all pharmaceuticals locally manufactured and those imported (entering) or donated to countries to make sure that they meet the set or established international or national standards. Short of that countries will be wasting a lot of money using forex which has been borrowed in a form a loans procuring and distributing to its people substandard medications which will do more harm than good to its indigenous people and this is unethical per se to give people drugs not meeting required set international standards.

\section{References}

1. The Priorities Book: AARP Public Policy Priorities. Washington DC: AARP [downloadable PDF on the internet]. 2006 [cited 2006 Feb 22]. Available from: http://www.aarp.org/issues/policies/priorities_book/

2. Quick JD, Rankin JR, Laing RO, O'Connor RW, Hogerzeil HV, Dukes MN, Garnett A, editors. Managing Drug Supply: The Selection, Procurement, Distribution, and Use of Pharmaceuticals. $2^{\text {nd }}$ Ed. West Hartford, Connecticut: Management Sciences for Health, Inc; 1997. (p.275).

3. The World Health Organization [homepage on the Internet]. Geneva: World Health Organization; 2006. [updated 2006 Feb, cited 2006 Feb 22]. Available from: http://www.who.int/mediacentre/factsheets/fs275/en/

4. U.S. Food and Drug Administration [homepage on Internet]. Rockville, MD: Food and Drug Administration; 2005. [Cited 2006 Feb 22]. Available from: http://www.fda.gov/oc/initiatives/counterfeit/update2005.html

5. Amin AA, Snow RW, Kokwaro GO. The quality of sulphadoxinepyrimethamine and amodiaquine products in the Kenyan retail sector. J pyrimethamine and amodiaquine

6. Shakoor $\mathrm{O}$, Taylor RB and Behrens RH. Assessment of the incidence of substandard drugs in developing countries. Tropical Medicine and International Health 1997, 2(9):839-845.

7. Ahmed Abdo-Rabbo, Amal Bassili and Hoda Atta. The quality of antimalarials available in Yemen. Malaria Journal 2005, 4:28.

8. Kayumba PC, Risha PG, Shewiyo D et al. The quality of essential Antimicrobial and antimalarial drugs marketed in Rwanda and Tanzania: influence of tropical storage conditions on in vitro dissolution. Journal of Clinical Pharmacology and Therapeutics 2004, (4): 331-8.

9. Ogwal-Okeng J.W., Owino E., and Obua C. Chloroquine in the Ugandan market fails quality test: a pharmacovigilance study. African Health Sciences 2003, 3(1):2-7

10. Risha PG, Vervaet C, Vergote G, Van Bortel L and Remon JP. Drug formulations intended for the global market should be tested for stability under tropical climatic conditions. European Journal of Clinical Pharmacology 2003, 59:135-141.

11. Pitts P. $\mathbf{2 1}^{\mathrm{st}}$ Century Health Care Terrorism: The Perils of International Drug Counterfeiting. San Francisco: Centre for Medicines in the Public Interest [downloadable PDF file on the Internet]. 2005 [cited 2006 Feb 25]. Available from: http://www.pacificresearch.org/pub/sab/health/2005/21st_Century_Counterf eiting Report2.pdf

12. Layloff T., Drug manufacture, industrial pharmacy considerations, quality assurance and regulation. PowerPoint presentation, Management Sciences for Health, January 30 2006, Baltimore.

13. Cockburn R, Newton PN, Agyarko EK, Akunyili D, White N.J., The global threat of counterfeit drugs: why industry and governments must communicate the dangers. PLoS Med. 2005 Apr;2(4):e100. Epub 2005 Mar 14. [cited 2006 Feb 25]. Available from: http://medicine.plosjournals.org/perlserv/?request=getdocument\&doi=10.1371/journal.pmed.0020100

14. The World Health Organization [homepage on the Internet]. AIDS Epidemic Update 2005. Geneva: World Health Organization; 2005 Dec. [cited 2006 Feb 26]. Available from: http://www.who.int/hiv/epiupdates/en/index.html

15. U.S. Food and Drug Administration [homepage on Internet]. Rockville, MD: Food and Drug Administration; 2005. [Cited 2006 Feb 26]. Available from: http://www.fda.gov/ola/2005/counterfeit1101.html

16. S. Food and Drug Administration [homepage on Internet]. Combating Counterfeit Drugs. Rockville, MD: Food and Drug Administration; 2004 $\begin{array}{llll}\text { Counterfeit Drugs. Rockville, MD: Food and Drug Administration; } 2004 . \\ \text { [cited } & 2006 & \text { Feb } & \text { 26]. }\end{array}$ from:http://www.fda.gov/oc/initiatives/counterfeit/report02_04.html

17. The World Health Organization [homepage on the Internet]. Guidelines for the development of measures to combat counterfeit medicines. Geneva: World Health Organization; 1999. [cited 2006 Feb 26].Available from: http://www.who.int/medicines/publications/counterfeitguidelines/en/index.ht $\underline{\mathrm{mlt}}$

18. Houston S. Justice and HIV care in Africa-anti-retrovirals in perspective. Journal of the International Association of Physicians in AIDS Care 2002, 1 (2):78-83. 